Research Paper

\title{
Comparison of Clinicopathological Features and Prognosis between ALK Rearrangements and EGFR Mutations in Surgically Resected Early-stage Lung Adenocarcinoma
}

\author{
Pupu Li1,2,3, Qiongqiong Gao ${ }^{1,2,3}$, Xiangli Jiang1,2,3, Zhongli Zhan ${ }^{1,2,4}$, Qingna Yan ${ }^{1,2,4}$, Zhaona Li1,2,3 and \\ Chun Huang $1,2,3 \otimes$ \\ 1. Tianjin Medical University Cancer Institute \& Hospital, National Clinical Research Center for Cancer; \\ 2. Key Laboratory of Cancer Prevention and Therapy, Tianjin; Tianjin's Clinical Research Center for Cancer; \\ 3. Department of Thoracic Oncology, Tianjin Medical University Cancer Institute \& Hospital; \\ 4. Department of Pathology, Tianjin Lung Cancer Center, Tianjin Medical University Cancer Institute \& Hospital, Tianjin 300060, P.R. China \\ $\square$ Corresponding author: Chun Huang, Department of Thoracic Oncology, Tianjin Lung Cancer Center, Tianjin Cancer Institute \& Hospital, Tianjin Medical \\ University, Tianjin 300060, China. Phone: 86-22-23340123-3200, Fax: 86-22-23537796. E-mail: yellowpure@126.com \\ (C) Ivyspring International Publisher. This is an open access article distributed under the terms of the Creative Commons Attribution (CC BY-NC) license \\ (https://creativecommons.org/licenses/by-nc/4.0/). See http://ivyspring.com/terms for full terms and conditions.
}

Received: 2018.04.27; Accepted: 2018.10.27; Published: 2019.01.01

\begin{abstract}
Background: A number of mutations in key oncogenes have been identified as important for the initiation and maintenance of lung adenocarcinoma (LAC). This study elucidated the prevalence and prognostic significance of mutations in the epidermal growth factor receptor gene (EGFR) and rearrangements in the anaplastic lymphoma kinase gene $(A L K)$ in patients with surgically resected primary LAC.

Patients and Methods: We retrospectively analyzed 675 consecutive patients who underwent radical resection at a single institution. We concurrently analyzed mutations in EGFR and the Kirsten rat sarcoma viral oncogene homolog gene (KRAS) by reverse transcription (RT)-PCR, and investigated ALK rearrangements by immunohistochemistry. LAC with or without various oncogenic mutations was studied for clinicopathological features and their association with disease-free survival (DFS) and overall survival (OS).

Result: ALK rearrangements and EGFR mutations were detected in 75 and 312 patients, respectively, with coexistence in 5 cases. ALK rearrangements and mutations in EGFR and KRAS were mutually exclusive. Compared with patients with EGFR mutations, ALK rearrangements were more common in younger patients, and those with advanced tumors, lymph node metastases, and higher rates of postoperative adjuvant therapy. Histologically, EGFR mutations were more common than ALK rearrangements in patients with the acinar predominant subtype and the lepidic predominant subtype of LAC, whereas $A L K$ rearrangements were more frequent in the solid predominant subtype with mucin production and invasive mucinous adenocarcinomas. ALK-positive patients had a significantly worse DFS than those with EGFR mutations and wild-type (WT) patients. The mean OS after surgical procedures was significantly longer in EGFR-mutated versus WT patients. No significant differences were found in patients with ALK-positive tumors compared with EGFR-mutated and WT patients.

Conclusion: Clinicopathological features of LAC with ALK rearrangements differ from those of LAC with EGFR mutations. Patients with ALK rearrangements had a significantly worse DFS than those harboring EGFR mutations. Thus, ALK rearrangements are an adverse prognostic factor in surgically-resected LAC patients, while EGFR mutations are associated with a better prognosis.
\end{abstract}

Key words: ALK, EGFR, lung adenocarcinoma, histological subtype, DFS 


\section{Introduction}

Primary lung cancer remains the leading cause of cancer mortality in China [1]. Patients with non-small cell lung cancer (NSCLC) account for $\sim 80 \%$ of lung cancer cases, and have a poor 5-year survival rate. NSCLC is characterized by the accumulation [2] of multiple genetic alterations [3], oncogenic driver mutations, which constitutively activate signaling pathways, leading to uncontrolled cell growth and proliferation. A number of mutations in key oncogenes have been identified as important genetic alterations in lung adenocarcinoma (LAC), including genes encoding epidermal growth factor receptor (EGFR), Kirsten rat sarcoma viral oncogene homolog $(K R A S)$, and anaplastic lymphoma kinase (ALK). These genetic variations provide prognostic value, as well as being specific molecular targets for therapeutic intervention [4-6]. During the past decade, emerging targeted therapies have led to a pattern shift in lung cancer treatment. For instance, tyrosine kinase inhibitors (TKIs) targeting EGFR mutations and ALK rearrangements have shown significant clinical efficacy in treating patients with advanced NSCLC harboring corresponding mutations [7].

EGFR is a 486-amino acid, $170 \mathrm{kDa}$ receptor glycoprotein with a single transmembrane sequence that was first identified as a binding partner of EGF. As a member of the ErbB receptor TK family, EGFR has an extracellular ligand-binding domain, a transmembrane lipophilic segment, and an intracellular domain with TK activity. On binding a growth factor, EGFR is self-phosphorylated by TK, then it activates cell signaling pathways involved in regulation of the cell cycle, apoptosis, angiogenesis, and cellular proliferation. Specific EGFR mutations induce constant phosphorylation of EGFR, which activates downstream signals. EGFR dysregulation plays a crucial role in the pathogenesis and progression of NSCLC [8, 9], and these findings have led to the development of anticancer drugs. In the early 2000s, gefitinib and erlotinib were the first two EGFR TKIs to be investigated as inhibitors of the EGFR signaling pathway. They were studied in previously treated NSCLC patients [10], and have proven successful in controling this disease [11-13]. More recently, a randomized, international, open-label, phase 3 trial proved that osimertinib had significantly greater efficacy than platinum therapy plus pemetrexed in patients with T790M-positive advanced NSCLC in whom disease had progressed during first-line EGFR TKI therapy [14].

The echinoderm microtubule-associated proteinlike 4-anaplastic lymphoma kinase fusion gene (EML4-ALK), generally known as the ALK fusion gene, was first described in 2007 . The fusion results from a small inversion within chromosome $2 p$, leading to expression of a chimeric TK in which the $\mathrm{N}$-terminal half of EML4 is fused to the intracellular kinase domain of ALK. This then activates protein kinase domains and downstream signaling pathways that are important in tumorigenicity. EML4-ALK possesses powerful oncogenic activity both in vitro and in vivo [15, 16], which can be blocked by small-molecule inhibitors that target ALK, supporting a role for EML4-ALK as a key driver of lung tumorigenesis. The overall incidence of the $A L K$ fusion gene in patients with LAC is $5.2 \%-11.2 \%$ [17, 18]. Consequently, it is another important target in the treatment of NSCLC [16]. Crizotinib is an ALK-TKI that plays a central role in this context, having been granted approval by the FDA in 2011.

EGFR and $A L K$ are the two most important driver genes that have been found in $30 \%-40 \%$ and $2 \%-7 \%$ of NSCLC patients, respectively [19-21]; they have a higher prevalence in patients with adenocarcinoma, younger patients, women, Asians, and those who have never smoked. EGFR mutations and ALK rearrangements are expected to have intrinsic prognostic value for survival because of the favorable clinicopathologic features of tumor types with these mutations. This has been indicated in previous studies of patients with advanced or early NSCLC with EGFR mutations [5, 8, 22], and patients with EGFR wild-type (WT) lung adenocarcinomas with $A L K$ rearrangements[23]. However, few reports have specifically evaluated the prognostic difference of EGFR mutations and $A L K$ rearrangements in surgically resected LAC. Therefore, to clarify the role of these two oncogenic mutations in predicting the outcome of resected LAC, we comprehensively evaluated the prognostic significance of EGFR mutations and $A L K$ rearrangements on disease-free survival (DFS) and overall survival (OS) in patients with completely resected primary LAC at a single institution.

\section{Materials and methods}

\section{Study population and tumor tissue samples}

This study adhered to Reporting Recommendations for Tumor Marker Prognostic Studies guidelines [24]. Six hundred and seventy-five consecutive patients with primary LAC who underwent complete surgical resection were enrolled in this retrospective study. All patients were admitted to the Tianjin Medical University Cancer Institute and Hospital (Tianjin, China) between January 2011 and December 2015, and had a pathologically confirmed diagnosis. Patients who did not undergo curative resection or had a previous history of other cancers or had any anticancer therapies before surgery were excluded. 
None of the patients in the study cohort had received corresponding molecular targeted therapy before tumor recurrence. Patients with comorbidity that might have affected OS, such as advanced cardiovascular disease, were also excluded from the study.

Most of the patients at a locally advanced stage received two to four cycles of platinum-based adjuvant chemotherapy following surgery (platinumpemetrexed, taxol, or docetaxol). Clinical data were collected from the hospital's medical recording system and are described in Table 1. Tumors were staged pathologically according to the 8th edition of the tumor-node-metastasis (TNM) classification for lung cancer [25]. Histologic subtypes were determined according to the 2011 IASLC/ATS/ERS international multidisciplinary classification of LAC [26]. The morphology of all samples was reviewed by two experienced pathologists from Tianjin Lung Cancer Center (Z.Z. and Q.Y.) on a blinded basis. Formalin- fixed, paraffin-embedded (FFPE) tumor tissues collected in surgical resection were used. Patients with insufficient or poor-quality tissue for molecular analyses, or inconclusive $A L K$ rearrangements, were excluded.

Following tumor resection, the patients were followed up every 3 months during the first 2 years and every 6 to 12 months over the next 3 years. Tumor recurrence was identified using radiological examination or biopsy. In the majority of patients, interval computed tomography scans were available for review by one thoracic radiologist. DFS was measured from the day of tumor resection until tumor recurrence or death. OS, defined as the time from curative operation to death from any cause, is a direct measure of clinical benefit to the patient. Patients alive or lost to follow-up were censored. Patients without a known date of death were censored at the time of last follow-up. Informed consent was received from patients or their families, and this study was approved by the Research Ethics Committee of Tianjin Medical University Cancer Institute and Hospital.

\section{Mutation analysis}

The detection of $A L K$ rearrangements was performed using the fully-automated Ventana immunohistochemistry (IHC) assay on a Benchmark XT autostainer (Ventana Medical Systems, Inc., Tucson, AZ, USA) using monoclonal rabbit anti-human ALK antibody (clone D5F3; catalog no. 790-4794; Ventana Medical Systems, Inc.). The Optiview DAB IHC detection kit (catalog no. 860-099; Ventana Medical Systems, Inc.) was used according to the manufacturer's protocols. As previously reported [27-29], positive staining was indicated by strong granular staining in the tumor cell cytoplasm in any percentage of positive tumor cells; otherwise, the expression of
ALK was considered to be negative (a binary scoring system). ALK rearrangements and histologic subtypes were determined by two experienced pathologists from Tianjin Lung Cancer Center (Z.Z. and Q.Y.) on a blinded basis.

Table 1. Clinicopathologic characteristics of patients with adenocarcinoma

\begin{tabular}{|c|c|}
\hline Variable & n ( $\%)$ \\
\hline \multicolumn{2}{|l|}{ Age, years } \\
\hline$\geq 60$ & $355(52.6)$ \\
\hline$<60$ & $320(47.4)$ \\
\hline Median & 60 \\
\hline \multicolumn{2}{|l|}{ Sex } \\
\hline Male & $320(47.4)$ \\
\hline Female & $355(52.6)$ \\
\hline \multicolumn{2}{|l|}{ Smoking history ${ }^{a}$} \\
\hline Never & $376(55.7)$ \\
\hline Smoker & $299(44.3)$ \\
\hline \multicolumn{2}{|l|}{ ECOG PS } \\
\hline 0 & $358(53.0)$ \\
\hline 1 & $317(47.0)$ \\
\hline \multicolumn{2}{|l|}{ Family history of cancer } \\
\hline Yes & 132(19.6) \\
\hline No & $543(80.4)$ \\
\hline \multicolumn{2}{|c|}{ Localization of primary tumor } \\
\hline LUL & 127(18.8) \\
\hline LLL & $122(18.1)$ \\
\hline RUL & $203(30.1)$ \\
\hline RML & $55(8.1)$ \\
\hline RLL & 126(18.7) \\
\hline Others $^{b}$ & $42(6.2)$ \\
\hline \multicolumn{2}{|l|}{ Operating methods } \\
\hline Open thoracotomy & $389(57.6)$ \\
\hline Thoracoscopy & $286(42.4)$ \\
\hline \multicolumn{2}{|l|}{ Tumor size } \\
\hline$\geq 3$ & $330(48.9)$ \\
\hline$<3$ & $345(51.1)$ \\
\hline Median & 2.8 \\
\hline \multicolumn{2}{|l|}{ Lymph node metastasis } \\
\hline Yes & $229(33.9)$ \\
\hline No & $446(66.9)$ \\
\hline \multicolumn{2}{|l|}{ TNM Stage } \\
\hline I & $380(56.3)$ \\
\hline II & $73(10.8)$ \\
\hline III & $222(32.9)$ \\
\hline \multicolumn{2}{|l|}{ Adenocarcinoma subtype } \\
\hline \multicolumn{2}{|l|}{ Invasive ADCc } \\
\hline Lepidic & $126(18.7)$ \\
\hline Acinar & $283(41.9)$ \\
\hline Papillary & $50(7.4)$ \\
\hline Micropapillary & $32(4.7)$ \\
\hline Solid & 124(18.4) \\
\hline Variants of invasive ADC & $45(6.7)$ \\
\hline \multicolumn{2}{|l|}{ Minimally invasive ADC } \\
\hline Nonmucinous & $9(1.3)$ \\
\hline Mucinous & $6(0.9)$ \\
\hline \multicolumn{2}{|l|}{ Adjuvant therapyc } \\
\hline Yes & $360(53.3)$ \\
\hline No & $310(45.9)$ \\
\hline Unknown & $5(0.8)$ \\
\hline
\end{tabular}

aNever smokers have smoked $<100$ cigarettes in their lifetime; smokers have smoked $\geq 100$ cigarettes. ${ }^{b}$ Dragging in several lobes. ${ }^{c}$ Adjuvant therapy included chemotherapy, radiotherapy, and biotherapy.

ADC, Adenocarcinoma; RUL, right upper lobe; RML, right middle lobe; RLL, right lower lobe; LUL, left upper lobe; LLL, left lower lobe; ECOG PS, Eastern

Cooperative Oncology Group performance status score; TNM,

tumor-node-metastasis. 
DNA extraction, reverse transcription (RT)-PCR amplification, and direct sequencing were performed for the detection of EGFR/KRAS mutations. Genomic DNA was extracted from FFPE blocks divided into 10-15 4- $\mu \mathrm{m}$ thick sections. The purified PCR product was analyzed using an ABI 3130xl sequencer. PolyPhred software [30] was used to analyze the sequence. To validate RT-PCR results, all samples were assessed by direct DNA sequencing.

\section{Statistical analysis}

The associations of genotype with clinicopathological characteristics and treatment types were assessed by Fisher's exact test for categorical data, and the Wilcoxon rank sum test for continuous data. DFS and OS were plotted using the Kaplan-Meier method, and the difference between genotypes was compared using the log-rank test. The Cox multivariate proportional hazard model was used for multivariate survival analysis, and hazard ratios (HRs) and 95\% confidence intervals (CIs) were calculated. All statistical tests were performed using SPSS version 20.0 software (SPSS Inc., Chicago, IL, USA). Values of $P<0.05$ for the two-tailed test were considered to indicate a statistically significant difference.

\section{Results}

\section{Patient characteristics}

A total of 675 patients with LAC (320 males and 355 females) were enrolled in this study, with a median age of 60 years (range, 28-79 years). All patients were diagnosed at various clinical stages according to the latest edition of the TNM Classification for lung cancer: 380 patients at stage I, 73 at stage II, and 222 at stage III. Postoperative adjuvant therapy (chemotherapy, radiotherapy, or biotherapy) was administered to 360 patients. Patient clinicopathologic characteristics are summarized in Table 1.

\section{Histological features}

The proportion of histopathologic subtypes, determined according to the 2011 IASLC/ATS/ERS international multidisciplinary classification of LAC [26], were invasive adenocarcinoma in 615 patients (91.1\%), with lepidic predominant, acinar predominant, papillary predominant, micropapillary predominant, and solid predominant with mucin production subtypes present in $126(18.7 \%), 283(41.9 \%), 50$ $(7.4 \%), 32(4.7 \%)$, and 124 patients $(18.4 \%)$, respectiveely; minimally invasive adenocarcinoma was seen in 15 patients $(2.2 \%)$, and variants of invasive adenocarcinoma in 45 patients $(6.7 \%)$.

\section{Prevalence and baseline characteristics of the molecular genotypes}

KRAS mutation detection was not performed in 29 of the 675 patients because of a lack of specimens; otherwise there was sufficient tissue to undergo EGFR and KRAS mutation detection and ALK fusion gene assays. EGFR and KRAS mutations were detected in $312(46.2 \%)$ and $70(10.8 \%)$ patients, respectively. Seventy-five patients $(11.1 \%)$ were ALK fusionpositive, and the remaining $226(33.5 \%)$ were wild-type (WT) for EGFR, ALK, and KRAS (WT/WT/ WT). Genetic alterations in ALK, EGFR, and KRAS were mutually exclusive. However, the coexistence of EGFR mutations and $A L K$ rearrangement was detected in 5 patients. Two samples possessed both EGFR and KRAS mutations.

Among the 312 patients with EGFR mutations, $132(42.3 \%)$ had in-frame deletions in exon 19, 147 $(47.1 \%)$ had point mutations in exon 21 at L858, 12 $(3.8 \%)$ in exon 18 , and $13(4.2 \%)$ had in-frame insertions in exon 20. The remaining 10 (3.2\%) patients exhibited multiple mutations, of whom seven patients possessed sensitive mutations in exons 19 and 21, and three patients possessed sensitive and primarily resistant mutations in the exon 20 insertion.

$A L K$-positive patients were substantially younger $(55.3 \pm 9.0$ years old) than patients with EGFR mutations (59.6 \pm 8.2 years old) and those with a WT status (59.8 \pm 7.8 years old) $(P<0.05$ for both). EGFR mutations and $A L K$ rearrangements were more frequently found in women $(62.8 \%$ and $57.3 \%$, respectively), and nonsmokers $(67.6 \%$ and $69.3 \%$, respectively) ( $P<0.05$ for both). The frequency of $A L K$ rearrangement in never/light smokers was higher than in those with EGFR mutations, but the difference was not significant. The rate of pathological stage I disease was significantly higher among patients with EGFR mutations $(61.2 \%)$ than in those with $A L K$ rearrangements $(44.0 \% ; P<0.05)$. Lymph node metastasis and postoperative adjuvant therapy were more common in patients with $A L K$ rearrangements ( $48 \%$ and $64 \%$, respectively) than in those with EGFR mutations $(32.7 \%$ and $48.4 \%$, respectively) $(P<0.05)$. No significant differences in Eastern Cooperative Oncology Group performance status score, family history of cancer, surgical technique, or tumor diameter were found among the different genotypes (all $P>0.05$ ).

The localization of primary tumors in patients harboring EGFR mutations and ALK rearrangements was as follows: Compared with EGFR-mutated tumors, ALK-positive tumors occurred more frequently in multiple lobes $(13.3 \%$ vs $5.8 \% ; P=0.043)$, and were less common in the upper right lobe $(14.7 \%$ vs $30.8 \% ; P=0.006)$. 
Table 2. Clinical characteristics of EGFR/KRAS mutation status and $A L K$ rearrangement in patients with lung adenocarcinoma

\begin{tabular}{|c|c|c|c|c|c|c|c|}
\hline Variable & ALK & EGFR & KRAS & WTa & $p$ Value $^{\mathrm{b}}$ & & \\
\hline & & & & & ALK vs EGFR & ALK vs WT & EGFR vs WT \\
\hline Total evaluated & $75(11.1)$ & $312(46.2)$ & $70(10.8)$ & $226(33.5)$ & & & \\
\hline \multicolumn{8}{|l|}{ Age } \\
\hline Mean $\pm S D$ & $55.3 \pm 9.0$ & $59.6 \pm 8.2$ & $60.6 \pm 7.7$ & $59.8 \pm 7.8$ & $<0.001$ & $<0.001$ & 0.858 \\
\hline \multicolumn{8}{|l|}{ Gender } \\
\hline Male & $32(42.7)$ & $116(37.2)$ & $48(68.6)$ & $129(57.1)$ & 0.428 & 0.033 & $<0.001$ \\
\hline Female & $43(57.3)$ & $196(62.8)$ & $22(31.4)$ & $97(42.9)$ & & & \\
\hline \multicolumn{8}{|l|}{ Smoking history } \\
\hline Never & $52(69.3)$ & $211(67.6)$ & $21(30.0)$ & $98(43.4)$ & 0.89 & $<0.001$ & $<0.001$ \\
\hline Smoker & $23(30.7)$ & 101(32.4) & $49(70.0)$ & $128(56.6)$ & & & \\
\hline \multicolumn{8}{|l|}{ ECOG PS score } \\
\hline 0 & $47(62.7)$ & $168(53.8)$ & $32(45.7)$ & $117(51.8)$ & 0.196 & 0.11 & 0.662 \\
\hline 1 & $28(37.3)$ & $144(46.2)$ & $38(54.3)$ & $109(48.2)$ & & & \\
\hline \multicolumn{8}{|l|}{ Family history of cancer } \\
\hline Yes & $14(18.7)$ & $58(18.6)$ & $11(15.7)$ & $50(22.1)$ & 1 & 0.626 & 0.328 \\
\hline No & 61(81.3) & $254(81.4)$ & $59(84.3)$ & $176(77.9)$ & & & \\
\hline \multicolumn{8}{|l|}{ Localization of primary tumor } \\
\hline LUL & $14(18.7)$ & $60(19.2)$ & $15(21.4)$ & $41(18.1)$ & 0.027 & 0.004 & 0.865 \\
\hline LLL & $16(21.3)$ & $56(17.9)$ & $14(20.0)$ & $40(17.7)$ & & & \\
\hline RUL & $11(14.7)$ & $96(30.8)$ & $18(25.7)$ & $78(34.5)$ & & & \\
\hline RML & $6(8.0)$ & $27(8.7)$ & $6(8.6)$ & $16(7.1)$ & & & \\
\hline RLL & $18(24.0)$ & $55(17.6)$ & $12(17.1)$ & $42(18.6)$ & & & \\
\hline Others & 10(13.3) & $18(5.8)$ & $5(7.1)$ & $9(4.0)$ & & & \\
\hline \multicolumn{8}{|l|}{ Operating technique } \\
\hline Open thoracotomy & $45(60.0)$ & $164(52.6)$ & $52(74.3)$ & $131(58.0)$ & 0.302 & 0.788 & 0.22 \\
\hline Thoracoscopy & $30(40.0)$ & $148(47.4)$ & $18(25.7)$ & $95(42.0)$ & & & \\
\hline \multicolumn{8}{|l|}{ Tumor diameter(cm) } \\
\hline Mean \pm SD & $3.1 \pm 1.8$ & $2.8 \pm 1.3$ & $3.5 \pm 1.9$ & $3.3 \pm 2.0$ & 0.666 & 0.391 & 0.054 \\
\hline \multicolumn{8}{|l|}{ Tumor stage } \\
\hline $\mathrm{T} 1$ & $43(57.3)$ & $211(67.6)$ & $38(54.3)$ & $133(58.8)$ & 0.153 & 0.815 & 0.111 \\
\hline $\mathrm{T} 2$ & $17(22.7)$ & $67(21.5)$ & $21(30.0)$ & $56(24.8)$ & & & \\
\hline $\mathrm{T} 3$ & $6(8.0)$ & 13(17.3) & $6(8.6)$ & $18(8.0)$ & & & \\
\hline $\mathrm{T} 4$ & $9(12.0)$ & $21(67.3)$ & $5(7.1)$ & $19(8.4)$ & & & \\
\hline \multicolumn{8}{|l|}{ Lymph node metastasis } \\
\hline Yes & $36(48.0)$ & $102(32.7)$ & $16(22.9)$ & $79(35.0)$ & 0.016 & 0.055 & 0.644 \\
\hline No & $39(52.0)$ & $210(67.3)$ & $54(77.1)$ & $147(65.0)$ & & & \\
\hline \multicolumn{8}{|l|}{ TNM Stage } \\
\hline I & $33(44.0)$ & 191(61.2) & $40(57.1)$ & $120(53.1)$ & $0.009 \mathrm{c}$ & $0.185^{c}$ & $0.064^{c}$ \\
\hline II & $13(17.3)$ & $20(6.4)$ & $12(17.1)$ & $30(13.3)$ & & & \\
\hline III & 29(38.7) & $101(32.4)$ & $18(25.7)$ & $76(33.6)$ & & & \\
\hline \multicolumn{8}{|l|}{ Adenocarcinoma subtype } \\
\hline Lepidic predominant & $5(6.7)$ & $74(23.7)$ & $4(5.7)$ & $44(19.5)$ & $<0.001$ & $<0.001$ & 0.058 \\
\hline Acinar predominant & $23(30.7)$ & $148(47.4)$ & $26(37.1)$ & $88(38.9)$ & & & \\
\hline Papillary predominant & $5(6.7)$ & $24(7.7)$ & $4(5.7)$ & $18(8.0)$ & & & \\
\hline Micropapillary predominant & $2(2.7)$ & $15(4.8)$ & $3(4.3)$ & $12(5.3)$ & & & \\
\hline Solid predominant & $25(33.3)$ & $35(11.2)$ & $22(31.4)$ & $44(19.5)$ & & & \\
\hline Invasive mucinous ADC & $15(20.0)$ & $10(3.2)$ & $7(10.0)$ & $13(5.8)$ & & & \\
\hline Others & 0 & $6(1.9)$ & $4(5.7)$ & $7(3.1)$ & & & \\
\hline \multicolumn{8}{|l|}{ Adjuvant therapy } \\
\hline Yes & $48(64.0)$ & $151(48.4)$ & $35(50.0)$ & $126(55.8)$ & 0.01 & 0.084 & 0.238 \\
\hline No & 25(33.3) & $159(51.0)$ & $35(50.0)$ & $99(43.8)$ & & & \\
\hline Unknown & $2(2.7)$ & $2(0.6)$ & 0 & $1(0.4)$ & & & \\
\hline
\end{tabular}

\section{Pathological subtype characteristics}

The predominant tumor subtypes in patients with EGFR mutations and ALK rearrangements patients are shown in Table 2. EGFR mutations were more common than $A L K$ rearrangements in patients with the acinar predominant subtype $(47.4 \%$ vs $30.7 \%$, respectively; $P=0.01$ ), and the lepidic predominant subtype $(23.7 \%$ vs $6.7 \%$, respectively; $P<0.05)$. Compared with EGFR mutations, ALK rearrangements were more frequently detected in the solid predominant subtype with mucin production $(33.3 \%$ vs $11.2 \%$, respectively) and invasive mucinous adenocarcinomas (20\% vs $3.2 \%$, respectively) $(P<0.05)$. 

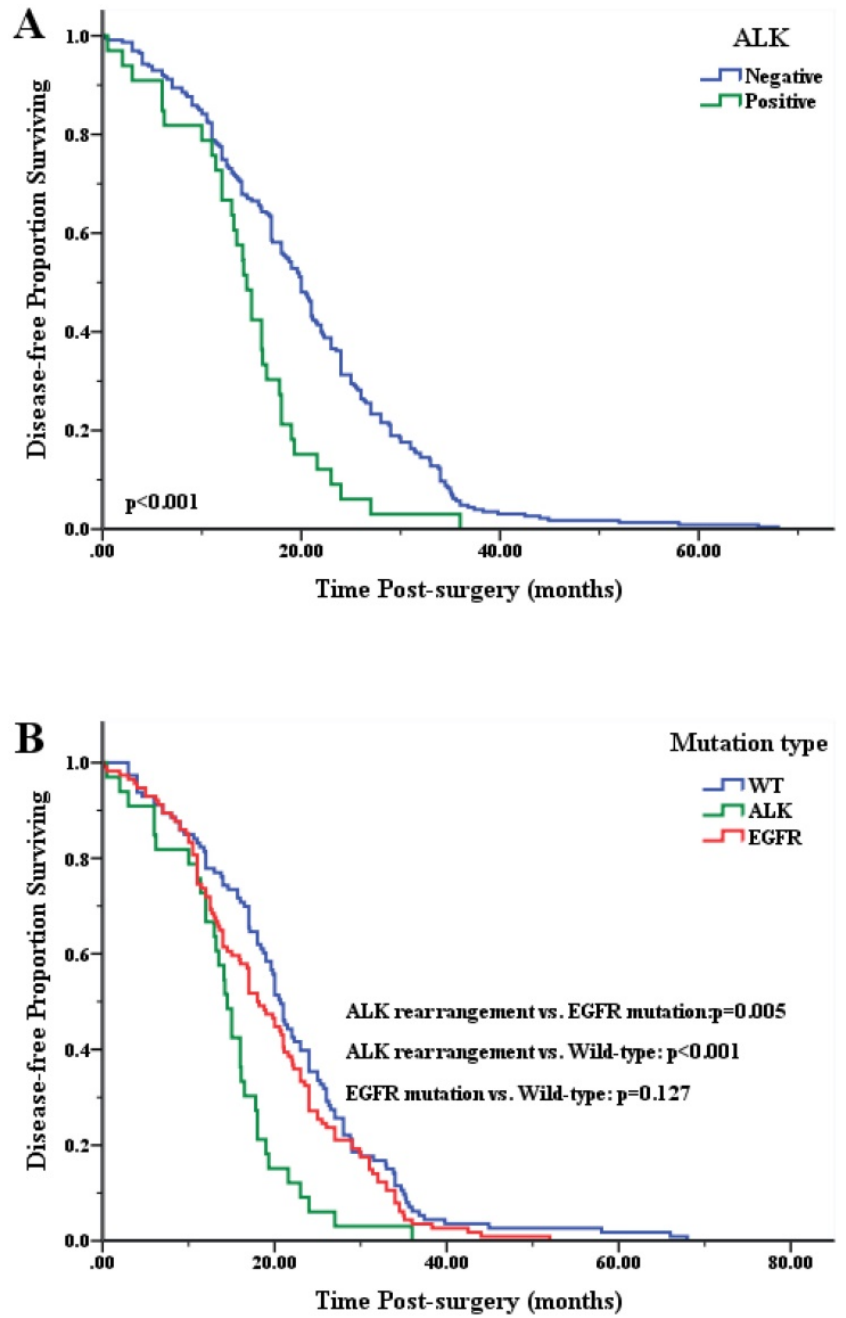

Figure 1. Comparison of disease-free survival (DFS) after surgery according to genotype. A. Kaplan-Meier survival curves for ALK-positive and ALK-negative patients. B. Pair-wise comparison of three groups.

\section{Clinical outcomes of LAC patients with EGFR mutations and $A L K$ rearrangements}

The median follow-up duration of all patients was 36.6 months (range, 25.0-84.3 months). As of February 1st, 2018, 546 patients $(80.9 \%)$ were still alive. However, except for two missing patients, 127 $(18.8 \%)$ of the 675 patients had died, of whom 112 $(95.9 \%)$ died from tumor-related causes, while four $(4.1 \%)$ had tumor-unrelated deaths (postoperative infection, postoperative respiratory and circulatory failure, heart disease, and accident). Causes of death were unknown in 11 patients.

To elucidate the relationship between the status of oncogenic driver mutations and clinical outcome of patients with LAC, we analyzed the DFS and OS of patients with or without mutations. Univariate analysis indicated that DFS and OS were significantly shorter in patients with a high tumor status, lymph node involvement, high TNM stage, and those with the lepidic predominant subtype and solid predominant with mucin production subtype. Additionally, EML4-ALK-positive patients had a significantly shorter DFS than EGFR mutation-positive and WT patients (both $P<0.05$ ) (Figure 1B). The mean OS after surgical procedures was significantly longer in EGFR-mutated patients (68.6 months) than WT patients (62.3 months) $(P=0.003)$. No significant differences were found in patients with $A L K$-positive tumors (57.0 months) compared with EGFR-mutated or WT patients (both $P>0.05$; Figure $2 \mathrm{~B}$ ).

To test the prognostic value of EGFR mutations and $A L K$ rearrangements, we performed multivariate analysis using the Cox proportional hazard model for all variables identified as significant by univariate analysis. Multivariate analyses of DFS and OS are shown in Table 3 and Table 4. Cox's proportional hazard model indicated that EGFR status was an independent variable for predicting OS $(P=0.003)$, while $A L K$ rearrangements were an independent variable for predicting DFS $(P<0.001)$.
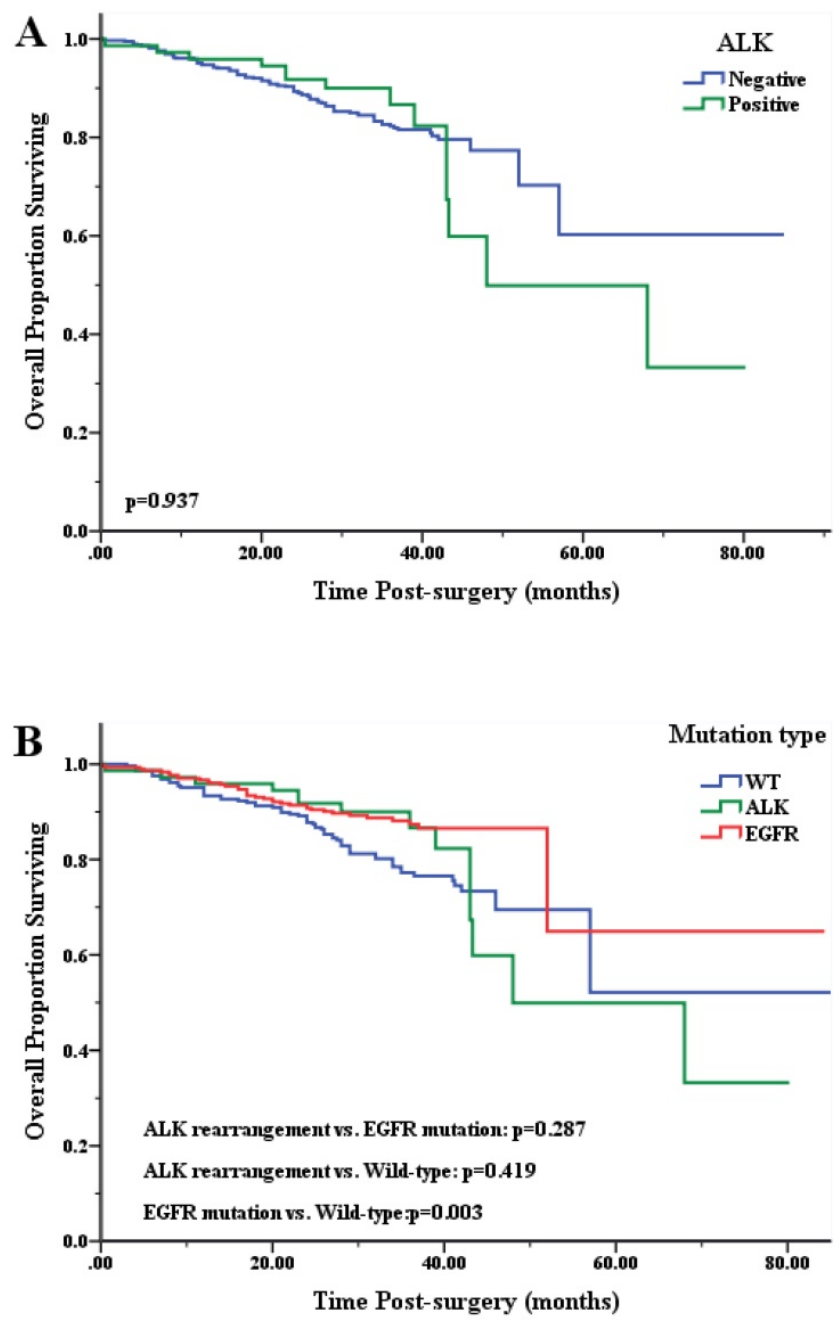

Figure 2. Kaplan-Meier curves plots for overall survival (OS) of LAC patients after surgery according to genotype. A. Curve for ALK-positive and ALK-negative patients. B. Pair-wise comparison of three groups. 
Table 3. Uni- and multivariate analyses of prognostic factors for disease-free survival

\begin{tabular}{|c|c|c|c|c|c|}
\hline \multirow[t]{2}{*}{ Variable } & \multirow{2}{*}{$\begin{array}{l}\text { No. of } \\
\text { recurrences }\end{array}$} & \multicolumn{2}{|l|}{ Univariate analysis } & \multicolumn{2}{|c|}{ Multivariate analysis } \\
\hline & & HR (95\% CI) & $p$-Valuea & HR (95\% CI) & $p$-Valuea \\
\hline \multicolumn{6}{|l|}{ Age } \\
\hline$<60$ & 132 & 1 & 0.283 & & \\
\hline$\geq 60$ & 123 & $1.144(0.895-1.463)$ & & & \\
\hline \multicolumn{6}{|l|}{ Gender } \\
\hline Female & 128 & 1 & 0.724 & & \\
\hline Male & 127 & $1.045(0.819-1.334)$ & & & \\
\hline \multicolumn{6}{|l|}{ ECOG PS } \\
\hline 0 & 110 & 1 & 0.046 & 1 & 0.042 \\
\hline 1 & 145 & $1.286(1.004-1.647)$ & & $1.299(1.009-1.671)$ & \\
\hline \multicolumn{6}{|l|}{ Operating technique } \\
\hline Thoracoscopy & 81 & 1 & 0.731 & & \\
\hline Open thoracotomy & 174 & $1.046(0.809-1.354)$ & & & \\
\hline \multicolumn{6}{|l|}{ T stage } \\
\hline $\mathrm{T} 1+2$ & 204 & 1 & 0.007 & & \\
\hline $\mathrm{T} 3+4$ & 51 & $1.524(1.121-2.072)$ & & & \\
\hline \multicolumn{6}{|c|}{ Lymph node metastasis } \\
\hline No & 122 & 1 & 0.019 & & \\
\hline Yes & 134 & $1.344(1.050-1.720)$ & & & \\
\hline \multicolumn{6}{|l|}{ pTNM stage } \\
\hline I+II & 110 & 1 & 0.001 & 1 & 0.001 \\
\hline III & 145 & 1.530(1.190-1.967) & & $1.598(1.240-2.059$ & \\
\hline \multicolumn{6}{|l|}{ Lepidic subtype } \\
\hline - & 218 & 1 & 0.257 & & \\
\hline+ & 37 & $0.817(0.576-1.159)$ & & & \\
\hline \multicolumn{6}{|l|}{ Solid subtype } \\
\hline- & 198 & 1 & 0.002 & 1 & 0.016 \\
\hline+ & 62 & $1.579(1.183-2.107)$ & & $1.438(1.071-1.930)$ & \\
\hline \multicolumn{6}{|l|}{ EGFR } \\
\hline+ & 108 & 1 & 0.476 & & \\
\hline- & 147 & $1.094(0.855-1.399)$ & & & \\
\hline \multicolumn{6}{|l|}{ ALK } \\
\hline- & 221 & 1 & $<0.001$ & 1 & $<0.001$ \\
\hline+ & 34 & $1.996(1.374-2.900)$ & & $1.974(1.347-2.893)$ & \\
\hline
\end{tabular}

ap-values were calculated using the Cox-proportional hazard model.

ALK, anaplastic lymphoma kinase; EGFR, epidermal growth factor receptor; ECOG PS, Eastern Cooperative Oncology Group performance status score; TNM, tumor-node-metastasis; HR, hazard ratio; CI, confidence interval.

Table 4. Uni- and multivariate analyses of prognostic factors for overall survival

\begin{tabular}{|c|c|c|c|c|c|}
\hline \multirow[t]{2}{*}{ Variable } & \multirow{2}{*}{$\begin{array}{l}\text { No. of } \\
\text { deaths }\end{array}$} & \multicolumn{2}{|l|}{ Univariate analysis } & \multicolumn{2}{|c|}{ Multivariate analysis } \\
\hline & & HR $(95 \% \mathrm{CI})$ & $p$-Value ${ }^{a}$ & HR $(95 \%$ CI) & $p$-Value \\
\hline \multicolumn{6}{|l|}{ Age } \\
\hline$<60$ & 57 & 1 & 0.753 & & \\
\hline$\geq 60$ & 59 & $0.943(0.655-1.358)$ & & & \\
\hline \multicolumn{6}{|l|}{ Gender } \\
\hline Female & 50 & 1 & 0.023 & & \\
\hline Male & 66 & $1.532(1.061-2.213)$ & & & \\
\hline \multicolumn{6}{|l|}{ ECOG PS } \\
\hline 0 & 44 & 1 & 0.034 & & \\
\hline 1 & 72 & $1.507(1.033-2.201)$ & & & \\
\hline \multicolumn{6}{|l|}{ Operating technique } \\
\hline Thoracoscopy & 32 & 1 & 0.008 & & \\
\hline Open thoracotomy & 84 & $1.716(1.149-2.563)$ & & & \\
\hline \multicolumn{6}{|l|}{ T stage } \\
\hline $1+2$ & 86 & $0.417(0.275-0.633)$ & $<0.001$ & & \\
\hline $3+4$ & 30 & 1 & & & \\
\hline \multicolumn{6}{|c|}{ Lymph node metastasis } \\
\hline No & 45 & $0.361(0.250-0.522)$ & $<0.001$ & & \\
\hline Yes & 71 & 1 & & & \\
\hline \multicolumn{6}{|l|}{ pTNM stage } \\
\hline $\mathrm{I}+\mathrm{II}$ & 44 & $0.266(0.183-0.388)$ & $<0.001$ & $0.274(0.188-0.400)$ & $<0.001$ \\
\hline III & 72 & 1 & & 1 & \\
\hline \multicolumn{6}{|l|}{ Lepidic subtype } \\
\hline- & 104 & 1 & 0.014 & & \\
\hline
\end{tabular}




\begin{tabular}{|c|c|c|c|c|c|}
\hline \multirow[t]{2}{*}{ Variable } & \multirow{2}{*}{$\begin{array}{l}\text { No. of } \\
\text { deaths }\end{array}$} & \multicolumn{2}{|l|}{ Univariate analysis } & \multicolumn{2}{|c|}{ Multivariate analysis } \\
\hline & & HR $(95 \%$ CI) & $p$-Value ${ }^{a}$ & HR (95\% CI) & $p$-Value ${ }^{a}$ \\
\hline+ & 12 & $0.470(0.258-0.856)$ & & & \\
\hline \multicolumn{6}{|c|}{ Solid subtype } \\
\hline- & 74 & 1 & $<0.001$ & 1 & $<0.001$ \\
\hline+ & 42 & $3.169(2.164-4.640)$ & & $2.580(1.753-3.798)$ & \\
\hline \multicolumn{6}{|l|}{ EGFR } \\
\hline+ & 35 & 1 & 0.003 & 1 & 0.003 \\
\hline- & 81 & $1.799(1.216-2.660)$ & & $1.814(1.223-2.693)$ & \\
\hline \multicolumn{6}{|c|}{ ALK fusion } \\
\hline+ & 14 & 1 & 0.937 & & \\
\hline- & 102 & $0.977(0.557-1.717)$ & & & \\
\hline
\end{tabular}

a p-values were calculated using the Cox-proportional hazard model.

ALK, anaplastic lymphoma kinase; EGFR, epidermal growth factor receptor; ECOG PS, Eastern Cooperative Oncology Group performance status score; TNM, tumor-node-metastasis; HR, hazard ratio; CI, confidence interval.

\section{Discussions}

The prognostic significance of EGFR mutations and ALK rearrangements in surgically resected LAC was unclear, so this study investigated clinicopathological features and compared outcomes between patients with these two types of genetic variations. We previously studied only ALK rearrangements in surgically-resected LAC patients; these subjects partially overlapped with those in the present study. In our earlier work [31], we suggested that the clinical characteristics of LAC patients with ALK rearrangements were similar to those of EGFR-mutated patients, and that $A L K$ rearrangements were an adverse prognostic factor. However, we did not determine the EGFR or KRAS status.

Individuals from Western countries are known to have lower rates of EGFR mutations and $A L K$ rearrangements than Asians [32, 33]. In the present study, we observed frequencies of $46.2 \%$ and $11.1 \%$, respectively, in resected LAC tissue. Consistent with previous studies [34,35], patients in both groups were more likely to be younger, female, and to be never or light smokers (Table 2). We also showed that ALKpositive patients exhibited characteristic clinical and pathological features compared with WT or those with EGFR mutations. Patients with ALK rearrangements were significantly younger than those with EGFR mutations $(P<0.001)$, while early-stage (stage I) LAC was more common in EGFR-mutated patients than those with $A L K$ rearrangements $(P<0.05)$. In LAC patients with $A L K$ rearrangements, the primary tumor site is more likely to simultaneously localize in multiple lobes, and less likely to be found in the upper right lobe than in those with EGFR mutations (Table 2 ). In the absence of appropriate genetic testing, these features may aid the differentiation of $A L K$ rearrangements from $E G F R$ mutations which is important because $A L K$-positive lung cancer is strongly associated with resistance to EGFR TKIs [15, 21].

$A L K$ rearrangements and EGFR mutations were previously reported to be mutually exclusive $[15,36$, 37]. In our study, $A L K$ rearrangements were more likely to occur in specimens without EGFR mutations $(P<0.05)$. However, an increasing number of studies [37-40] showed that ALK rearrangements can occur concurrently with EGFR mutations, typically at an incidence $<1 \%$ in NSCLC. We observed concomitant EGFR and ALK alterations in $0.74 \%$ of LAC patients and $6.7 \%$ of $A L K$-positive cases. KRAS mutations and $A L K$ rearrangements did not occur together in our cohort, and no cases exhibited all three driver gene mutations. Our results further indicate that $A L K$ rearrangements and EGFR and KRAS mutations are almost mutually exclusive within a single tumor [33].

The significant association noted between ALK rearrangements and EGFR mutations with histological subtypes is controversial. Several reports indicated that EGFR mutations are frequently associated with adenocarcinoma with a lepidic growth pattern [41, 42], while the solid predominant subtype with mucin production pattern and lack of lepidic growth was shown to be more common in ALK-positive patients $[2,43,44]$. Using the 2011 IASLC/ATS/ERS international multidisciplinary classification of LAC, our study showed that most tumors with $A L K$ rearrangements had a solid predominant subtype with mucin production or were invasive mucinous adenocarcinomas $(P<0.05)$. EGFR mutations were more common in patients with the acinar predominant subtype and the lepidic predominant subtype $(P<0.05)$. These results differed from previous studies. For example, Zaric et al. [45] showed that the acinar subtype of LAC was significantly $(P=0.02)$ associated with the EML4-ALK- positive mutation status, while Dong et al. [2] reported that EGFR mutations were more closely associated with the acinar predominant $(P=0.030)$ and papillary predominant $(P=0.006)$ subtypes. Additionally, ALK rearrangements occurred more commonly in tumors of the solid predominant subtype than other subtypes $(P=0.002)$, and less commonly in the papillary predominant subtype $(P=$ 0.004). Despite these reported differences, LAC histology is associated with EGFR mutation status, as seen by the higher frequency of EGFR mutations in 
tumors with acinar and lepidic patterns than those with a solid pattern [46].

Several studies have shown that EGFR mutations might be a prognostic predictor for patients with advanced or early NSCLC. Sonobe et al. [5] indicated that stage I adenocarcinoma or large cell carcinoma patients with EGFR-mutated tumors have a higher 5-year survival rate than those with EGFR WT tumors $(P=0.037)$. Similarly, Chao et al. [47] revealed that patients with EGFR-mutated tumors had significantly longer OS than those with EGFR-WT tumors ( $P=$ 0.002), while Izar et al. found that EGFR mutations were an independent prognostic factor in completely resected stage I NSCLC [48]. We observed a significantly longer mean OS after surgical procedures in EGFR-mutated patients than WT patients $(P=$ $0.003)$, which is consistent with previous studies.

Yang et al. reported that $A L K$ rearrangements were significantly associated with poor DFS in never-smoker patients with surgically resected LAC [49]. Zhou et al. also found that ALK rearrangements were significantly associated with poor prognosis in a stage IIIA subgroup of NSCLC patients. However, in stage IA NSCLC, ALK-positive patients had longer DFS than $A L K$-negative patients [4]. In our present study, patients with EML4-ALK fusions had a significantly shorter DFS than those with EGFR mutations or WT patients. However, there was no difference in OS. Multivariate analysis also identified EML4-ALK fusion as an independent factor for poor DFS (but not OS) in our study. However, Blackhall et al. [50] showed that $A L K$ positivity was a predictor for better OS in patients with surgically resected LAC, while Kim et al. [46] revealed that the median OS was longer in $A L K$-positive lung cancer patients than in EGFR-positive or WT patients. The prognostic significance of $A L K$ rearrangements in surgically resected LAC therefore remains inconclusive.

Few studies have made a prognostic comparison of EGFR mutations and $A L K$ rearrangements in patients after surgical resection of early LAC. Kim et al. [46] reported a significantly longer median OS after surgical procedures in $A L K$-positive patients compared with those patients with EGFR mutations $(P=0.0266)$. We observed a significantly worse DFS in EML4-ALK-positive patients compared with EGFR-mutated ones $(P=0.012)$. However, there was no significant difference in mean OS between the two groups ( $P>0.05$, Figure 2$)$.

The current study has some limitations. It was a retrospective study conducted in a single large institution. Therefore, our findings should be validated by a prospective study of a larger sample from multiple centers. Moreover, because our study reviewed patients from January 2011 to December
2015, we were unable to obtain complete prognostic information, so some 3-year and 5-year survival data are missing. Therefore, the follow-up duration needs to be extended for OS analysis. Additionally, future analysis should obtain details about treatment after tumor recurrence, which could influence the results. Nevertheless, our results are promising, and we are encouraged to confirm them in longer follow-up research and to conduct additional studies on patients with mutations in other oncogenes.

In conclusion, we demonstrated that younger patients, those with the solid predominant subtype with mucin production and invasive mucinous adenocarcinoma, a higher defined TNM stage, and lymph node metastasis were more likely to harbor $A L K$ rearrangements than EGFR mutations in early-stage surgically resected LAC. Patients with $A L K$ rearrangements had a significantly worse DFS than those with EGFR mutations, indicating that ALK rearrangements are an adverse prognostic factor, while EGFR mutations are associated with a better prognosis.

\section{Abbreviations}

NSCLC: non-small cell lung cancer; LAC: lung adenocarcinoma; ALK: anaplastic lymphoma kinase; EGFR: epidermal growth factor receptor; KRAS: kirsten rat sarcoma viral oncogene homolog; DFS: disease-free survival; OS: overall survival; TKI: tyrosine kinase inhibitor; FFPE: formalin-fixed paraffin embedded; IHC: immunohistochemistry; RT-PCR: real-time quantitative reverse transcription-polymerase chain reaction; TNM: tumor-node-metastasis; ECOG PS: Eastern Cooperative Oncology Group performance status score; HR: hazard ratio; CI: confidence interval.

\section{Supplementary Material}

Supplementary table S1.

http://www.jcancer.org/v10p0061s1.pdf

\section{Acknowledgments}

We gratefully recognize the patients who participated in this study. This work was supported by grants from the National Natural Science Foundation of China (NO. 81372467 and NO.81501988).

\section{Competing Interests}

The authors have declared that no competing interest exists.

\section{References}

1. Chen W, Zheng R, Baade PD, Zhang S, Zeng H, Bray F, et al. Cancer statistics in China, 2015. CA: a cancer journal for clinicians. 2016; 66: 115-32.

2. Dong Y-J, Cai Y-R, Zhou L-J, Su DAN, Mu J, Chen X-J, et al. Association between the histological subtype of lung adenocarcinoma, EGFR/KRAS 
mutation status and the ALK rearrangement according to the novel IASLC/ATS/ERS classification. Oncology letters. 2016; 11: 2552-8.

3. Kalikaki A, Koutsopoulos A, Trypaki M, Souglakos J, Stathopoulos E, Georgoulias V, et al. Comparison of EGFR and K-RAS gene status between primary tumours and corresponding metastases in NSCLC. British journal of cancer. 2008; 99: 923-9.

4. Zhou JX, Yang H, Deng Q, Gu X, He P, Lin Y, et al. Oncogenic driver mutations in patients with non-small-cell lung cancer at various clinical stages. Annals of oncology : official journal of the European Society for Medical Oncology. 2013; 24: 1319-25.

5. Sonobe M, Nakagawa M, Takenaka K, Katakura H, Adachi M, Yanagihara K, et al. Influence of epidermal growth factor receptor (EGFR) gene mutations on the expression of EGFR, phosphoryl-Akt, and phosphoryl-MAPK, and on the prognosis of patients with non-small cell lung cancer. Journal of surgical oncology. 2007; 95: 63-9.

6. Guan JL, Zhong WZ, An SJ, Yang JJ, Su J, Chen ZH, et al. KRAS mutation in patients with lung cancer: a predictor for poor prognosis but not for EGFR-TKIs or chemotherapy. Annals of surgical oncology. 2013; 20: 1381-8.

7. Tufman A, Kahnert K, Duell T, Kauffmann-Guerrero D, Milger K, Schneider $\mathrm{C}$, et al. Frequency and clinical relevance of EGFR mutations and EML4-ALK translocations in octogenarians with non-small cell lung cancer. OncoTargets and therapy. 2017; 10: 5179-86.

8. Nishii T, Yokose T, Miyagi Y, Daigo Y, Isaka T, Furumoto H, et al. Prognostic value of EGFR mutations in surgically resected pathological stage I lung adenocarcinoma. Asia-Pacific journal of clinical oncology. 2017; 13: e204-e11.

9. Littlefield P, Jura N. EGFR lung cancer mutants get specialized. Proceedings of the National Academy of Sciences of the United States of America. 2013; 110: 15169-70.

10. Lee DH. Treatments for EGFR-mutant non-small cell lung cancer (NSCLC): The road to a success, paved with failures. Pharmacology \&amp; therapeutics. 2017; 174: 1-21.

11. Lynch TJ, Bell DW, Sordella R, Gurubhagavatula S, Okimoto RA, Brannigan $\mathrm{BW}$, et al. Activating mutations in the epidermal growth factor receptor underlying responsiveness of non-small-cell lung cancer to gefitinib. The New England journal of medicine. 2004; 350: 2129-39.

12. Park K, Yu CJ, Kim SW, Lin MC, Sriuranpong V, Tsai CM, et al. First-Line Erlotinib Therapy Until and Beyond Response Evaluation Criteria in Solid Tumors Progression in Asian Patients With Epidermal Growth Factor Receptor Mutation-Positive Non-Small-Cell Lung Cancer: The ASPIRATION Study. JAMA oncology. 2016; 2: 305-12.

13. Coudert B, Ciuleanu T, Park K, Wu YL, Giaccone G, Brugger W, et al. Survival benefit with erlotinib maintenance therapy in patients with advanced non-small-cell lung cancer (NSCLC) according to response to first-line chemotherapy. Annals of oncology : official journal of the European Society for Medical Oncology. 2012; 23: 388-94.

14. Mok TS, Wu YL, Ahn MJ, Garassino MC, Kim HR, Ramalingam SS, et al. Osimertinib or Platinum-Pemetrexed in EGFR T790M-Positive Lung Cancer. The New England journal of medicine. 2017; 376: 629-40.

15. Shaw AT, Yeap BY, Mino-Kenudson M, Digumarthy SR, Costa DB, Heist RS, et al. Clinical features and outcome of patients with non-small-cell lung cancer who harbor EML4-ALK. Journal of clinical oncology : official journal of the American Society of Clinical Oncology. 2009; 27: 4247-53.

16. Tao H, Cai Y, Shi L, Tang J, Liu Z, Wang Z, et al. Analysis of clinical characteristics and prognosis of patients with anaplastic lymphoma kinase-positive and surgically resected lung adenocarcinoma. Thoracic cancer. 2017; 8: 8-15.

17. Paik JH, Choi CM, Kim H, Jang SJ, Choe G, Kim DK, et al. Clinicopathologic implication of ALK rearrangement in surgically resected lung cancer: a proposal of diagnostic algorithm for ALK-rearranged adenocarcinoma. Lung cancer. 2012; 76: 403-9.

18. Kang HJ, Lim HJ, Park JS, Cho YJ, Yoon HI, Chung JH, et al. Comparison of clinical characteristics between patients with ALK-positive and EGFR-positive lung adenocarcinoma. Respiratory medicine. 2014; 108: 388-94.

19. Yatabe $Y$, Kerr KM, Utomo A, Rajadurai P, Tran VK, Du X, et al. EGFR mutation testing practices within the Asia Pacific region: results of a multicenter diagnostic survey. Journal of thoracic oncology : official publication of the International Association for the Study of Lung Cancer. 2015; 10: 438-45

20. Tan DS, Mok TS, Rebbeck TR. Cancer Genomics: Diversity and Disparity Across Ethnicity and Geography. Journal of clinical oncology : official journal of the American Society of Clinical Oncology. 2016; 34: 91-101.

21. Gridelli C, de Marinis F, Cappuzzo F, Di Maio M, Hirsch FR, Mok T, et al. Treatment of advanced non-small-cell lung cancer with epidermal growth factor receptor (EGFR) mutation or ALK gene rearrangement: results of an international expert panel meeting of the Italian Association of Thoracic Oncology. Clinical lung cancer. 2014; 15: 173-81.

22. Wu M, Zhao J, Song SW, Zhuo M, Wang X, Bai H, et al. EGFR mutations are associated with prognosis but not with the response to front-line chemotherapy in the Chinese patients with advanced non-small cell lung cancer. Lung cancer. 2010; 67: 343-7.

23. Wu SG, Kuo YW, Chang YL, Shih JY, Chen YH, Tsai MF, et al. EML4-ALK translocation predicts better outcome in lung adenocarcinoma patients with wild-type EGFR. Journal of thoracic oncology : official publication of the International Association for the Study of Lung Cancer. 2012; 7: 98-104.
24. McShane LM, Altman DG, Sauerbrei W, Taube SE, Gion M, Clark GM, et al. REporting recommendations for tumor MARKer prognostic studies (REMARK). Nature clinical practice Urology. 2005; 2: 416-22.

25. Goldstraw P, Chansky K, Crowley J, Rami-Porta R, Asamura H, Eberhardt WE, et al. The IASLC Lung Cancer Staging Project: Proposals for Revision of the TNM Stage Groupings in the Forthcoming (Eighth) Edition of the TNM Classification for Lung Cancer. Journal of thoracic oncology : official publication of the International Association for the Study of Lung Cancer. 2016; $11: 39-51$

26. Travis WD, Brambilla E, Noguchi M, Nicholson AG, Geisinger KR, Yatabe Y, et al. International association for the study of lung cancer/american thoracic society/european respiratory society international multidisciplinary classification of lung adenocarcinoma. Journal of thoracic oncology : official publication of the International Association for the Study of Lung Cancer. 2011; 6: 244-85

27. Ying J, Guo L, Qiu T, Shan L, Ling Y, Liu X, et al. Diagnostic value of a novel fully automated immunochemistry assay for detection of ALK rearrangement in primary lung adenocarcinoma. Annals of oncology : official journal of the European Society for Medical Oncology. 2013; 24: 2589-93.

28. Vinciguerra GLR, Scarpino S, Pini B, Cippitelli C, Fochetti F, Ruco L. Optimized immunohistochemistry using the D5F3 antibody provides a reliable test for identification of ALK-positive lung adenocarcinomas. Virchows Archiv : an international journal of pathology. 2017; 471: 123-7.

29. von Laffert M, Schirmacher P, Warth A, Weichert W, Buttner R, Huber RM, et al. ALK-Testing in non-small cell lung cancer (NSCLC): Immunohistochemistry (IHC) and/or fluorescence in-situ Hybridisation (FISH)?: Statement of the Germany Society for Pathology (DGP) and the Working Group Thoracic Oncology (AIO) of the German Cancer Society e.V. (Stellungnahme der Deutschen Gesellschaft fur Pathologie und der AG Thorakale Onkologie der Arbeitsgemeinschaft Onkologie/Deutsche Krebsgesellschaft e.V.). Lung cancer. 2017; 103: 1-5.

30. Nickerson DA, Tobe VO, Taylor SL. PolyPhred: automating the detection and genotyping of single nucleotide substitutions using fluorescence-based resequencing. Nucleic acids research. 1997; 25: 2745-51.

31. Gao Q, Li P, Jiang X, Zhan Z, Yan Q, Zhang B, et al. Worse disease-free, tumor-specific, and overall survival in surgically-resected lung adenocarcinoma patients with ALK rearrangement. Oncotarget. 2017; 8: 86066-81.

32. Maki-Nevala S, Ronty M, Morel M, Gomez M, Dawson Z, Sarhadi VK, et al. Epidermal growth factor receptor mutations in 510 Finnish non--small-cell lung cancer patients. Journal of thoracic oncology : official publication of the International Association for the Study of Lung Cancer. 2014; 9: 886-91.

33. Kometani T, Sugio K, Osoegawa A, Seto T, Ichinose Y. Clinicopathological features of younger (aged $</=50$ years) lung adenocarcinoma patients harboring the EML4-ALK fusion gene. Thoracic cancer. 2018.

34. Miao Y, Zhu S, Li H, Zou J, Zhu Q, Lv T, et al. Comparison of clinical and radiological characteristics between anaplastic lymphoma kinase rearrangement and epidermal growth factor receptor mutation in treatment naive advanced lung adenocarcinoma. Journal of thoracic disease. 2017; 9: 3927-37

35. Fukui T, Yatabe Y, Kobayashi Y, Tomizawa K, Ito S, Hatooka S, et al. Clinicoradiologic characteristics of patients with lung adenocarcinoma harboring EML4-ALK fusion oncogene. Lung cancer. 2012; 77: 319-25.

36. Kosaka T, Yatabe Y, Onozato R, Kuwano H, Mitsudomi T. Prognostic implication of EGFR, KRAS, and TP53 gene mutations in a large cohort of Japanese patients with surgically treated lung adenocarcinoma. Journal of thoracic oncology : official publication of the International Association for the Study of Lung Cancer. 2009; 4: 22-9.

37. Tian HX, Zhang XC, Yang JJ, Guo WB, Chen ZH, Wang Z, et al. Clinical characteristics and sequence complexity of anaplastic lymphoma kinase gene fusions in Chinese lung cancer patients. Lung cancer. 2017; 114: 90-5.

38. Lo Russo G, Imbimbo M, Corrao G, Proto C, Signorelli D, Vitali M, et al. Concomitant EML4-ALK rearrangement and EGFR mutation in non-small cell lung cancer patients: a literature review of 100 cases. Oncotarget. 2017; 8: 59889-900

39. Caliez J, Monnet I, Pujals A, Rousseau-Bussac G, Jabot L, Boudjemaa A, et al. [Lung adenocarcinoma with concomitant EGFR mutation and ALK rearrangement]. Revue des maladies respiratoires. 2017; 34: 576-80.

40. Brcic L, Jakopovic M, Misic M, Seiwerth F, Kern I, Smojver-Jezek S, et al. Analysis of the frequency of EGFR, KRAS and ALK mutations in patients with lung adenocarcinoma in Croatia. Diagnostic pathology. 2016; 11: 90.

41. Miller VA, Kris MG, Shah N, Patel J, Azzoli C, Gomez J, et al. Bronchioloalveolar pathologic subtype and smoking history predict sensitivity to gefitinib in advanced non-small-cell lung cancer. Journal of clinical oncology : official journal of the American Society of Clinical Oncology. 2004; 22. 1103-9.

42. Haneda H, Sasaki H, Shimizu S, Endo K, Suzuki E, Yukiue H, et al. Epidermal growth factor receptor gene mutation defines distinct subsets among small adenocarcinomas of the lung. Lung cancer. 2006; 52: 47-52.

43. Yoshida A, Tsuta K, Nakamura H, Kohno T, Takahashi F, Asamura H, et al. Comprehensive histologic analysis of ALK-rearranged lung carcinomas. The American journal of surgical pathology. 2011; 35: 1226-34.

44. Travis WD, Brambilla E, Noguchi M, Nicholson AG, Geisinger K, Yatabe Y, et al. International Association for the Study of Lung Cancer/American Thoracic Society/European Respiratory Society: international multidisciplinary 
classification of lung adenocarcinoma: executive summary. Proceedings of the American Thoracic Society. 2011; 8: 381-5.

45. Zaric B, Stojsic V, Panjkovic M, Tegeltija D, Stepanov V, Kovacevic T, et al. Clinicopathological features and relation between anaplastic lymphoma kinase (ALK) mutation and histological subtype of lung adenocarcinoma in Eastern European Caucasian population. Journal of Cancer. 2016; 7: 2207-12.

46. Kim TJ, Lee CT, Jheon SH, Park JS, Chung JH. Radiologic Characteristics of Surgically Resected Non-Small Cell Lung Cancer With ALK Rearrangement or EGFR Mutations. The Annals of thoracic surgery. 2016; 101: 473-80.

47. Chao L, Yi-Sheng H, Yu C, Li-Xu Y, Xin-Lan L, Dong-Lan L, et al. Relevance of EGFR mutation with micropapillary pattern according to the novel IASLC/ATS/ERS lung adenocarcinoma classification and correlation with prognosis in Chinese patients. Lung cancer. 2014; 86: 164-9.

48. Izar B, Sequist L, Lee M, Muzikansky A, Heist R, Iafrate J, et al. The impact of EGFR mutation status on outcomes in patients with resected stage I non-small cell lung cancers. The Annals of thoracic surgery. 2013; 96: 962-8.

49. Yang P, Kulig K, Boland JM, Erickson-Johnson MR, Oliveira AM, Wampfler J, et al. Worse disease-free survival in never-smokers with ALK+ lung adenocarcinoma. Journal of thoracic oncology : official publication of the International Association for the Study of Lung Cancer. 2012; 7: 90-7.

50. Blackhall FH, Peters S, Bubendorf L, Dafni U, Kerr KM, Hager H, et al. Prevalence and clinical outcomes for patients with ALK-positive resected stage I to III adenocarcinoma: results from the European Thoracic Oncology Platform Lungscape Project. Journal of clinical oncology : official journal of the American Society of Clinical Oncology. 2014; 32: 2780-7. 